\title{
Prehistoria y Primatología: estudio de la conducta instrumental en primates no humanos
}

\author{
Prehistory and Primatology: the Tool Behaviour Case in \\ Non-Human Primates
}

\author{
Daniel García-Raso \\ Departamento de Prehistoria. Departamento de Psicobiología. Universidad Complutense de Madrid \\ danielcbq@hotmail.com
}

Recibido: 07-09-2011

Aceptado: 20-01-2012

\begin{abstract}
RESUMEN
El conocimiento prehistórico se nutre de muchas ciencias y disciplinas auxiliares (Geología, Arqueología, Antropología, Etnoarqueología, etc.) para conformarse paradigmáticamente. Sin embargo, en el ámbito académico español (y en gran medida también en el europeo) existen algunas fuentes de información interpretativa que no han logrado la misma atención. Tal es el caso de la Primatología, que si bien es una herramienta muy utilizada entre los investigadores anglófonos, apenas ha sido manejada por los prehistoriadores españoles. En este artículo intentaremos llenar ese vacio presentando una síntesis teórica y bibliográfica sobre uno de los aspectos conductuales de los primates no humanos que guarda una relación más estrecha con la Prehistoria: el uso y fabricación de herramientas, o lo que es lo mismo, la conducta instrumental. Veremos también, finalmente, cómo y de qué manera la relación entre Prehistoria y Primatología puede dar sus mejores resultados mediante el uso de la analogía.
\end{abstract}

Palabras Clave: Etología. Primatología. Conducta instrumental. Primeros homínidos. Analogía.

\begin{abstract}
Prehistoric archaeology is constructed paradigmatically through a great variety of auxiliary sciences, including Geology, Archaeology, Anthropology or Ethnoarchaeology. However, in the Spanish disciplinary context (and also in the 'continental' European to a great extent) there are several theoretical and practical domains which are not fully exploited. This is the case of Primatology, a recurrent scientific tool among prehistory researchers in the Anglophone world that has been hardly utilized by Spanish prehistorians. In this paper, we try to fill this gap with a synthesis about one of the most important behavioural issues of non-human primates, which has a clear connection with Prehistory: tool use and tool making, i.e. tool behaviour. Proposals concerning how and in which ways the relationship between Prehistory and Primatology could be profitable exploited through the use of analogy will end this paper.
\end{abstract}

KEY WORDs: Ethology. Primatology. Tool behaviour. Early hominids. Analogy.

Sumario 1. Introducción. 2. ¿Qué es la conducta instrumental? 3. Conducta instrumental en primates no humanos: algunos ejemplos ilustrativos. 3.1. Prosimios. 3. 2. Antropoides: el Nuevo Mundo (calitrícidos y cébidos). 3. 3. Antropoides: el Viejo Mundo (cercopitecinos). 3. 4. Antropoides: el Viejo Mundo (hominoideos). 4. Conclusiones. 


\section{Introducción}

Para solucionar un problema científico, según lo define buena parte de la epistemología (e. g. Kuhn 2000; Lakatos 1974; Popper 2007), cualquier tipo de información, observación, comparación o análisis que sea pertinente al problema es también válido, pues nos ayuda a desentrañar aquello que no podemos contemplar de una forma clara. Gran parte del avance de la ciencia, por tanto, reside en el flujo de información que se establece entre distintas disciplinas, el cual puede hacer que el problema que tratamos de afrontar intelectualmente sea abordado desde una perspectiva renovada, más fructífera, que nos acerque un poco más a su significado real, a su validez científica. Prigogine y Stengers (2004: 314315) lo observan de esta manera:

Preguntas abandonadas o negadas por una disciplina han pasado en silencio a otra, han resurgido dentro de un nuevo contexto teórico. Su recorrido, subterráneo y de superficie, nos parece manifestar el sordo trabajo de algunas cuestiones que determinaron la profunda puesta en comunicación más allá de la proliferación de las disciplinas. Y es muchas veces en las intersecciones entre disciplinas, con ocasión de la convergencia entre vías separadas de aproximación, donde han resurgido problemas que creíamos saldados, que han podido insistir, bajo una forma renovada, antiguas preguntas, anteriores al enclaustramiento disciplinario.

Comenzamos de tal manera este artículo porque sabemos que el hecho de presentar en una revista de prehistoria una investigación que, en esencia, trata sobre animales no humanos no es lo más habitual en el ámbito académico peninsular y, salvo excepciones como la del Reino Unido, incluso en el europeo. Carencia que resulta difícil de entender, sobre todo teniendo en cuenta el carácter "oportunista" de la arqueología prehistórica que nunca se ha encerrado en sí misma y que trabaja junto a la geología, la biología, la historia, el arte o la antropología para construir sus hipótesis; y que goza, además, de una gran riqueza de paradigmas interpretativos o tendencias teóricas, lo cual es un síntoma de su buena salud epistemológica.

Sin embargo, el desinterés de la gran mayoría de los arqueólogos prehistóricos del sistema universitario español hacia el comportamiento de los primates, sus parientes biológicos más cercanos, es, a juicio de algún investigador más atrevido dentro de la disciplina, exasperante (Serrallonga 2005). Lo es aún más cuando esa desgana se prodiga también en el ámbito donde debería mostrar más interés, esto es, en el estudio del origen de la humanidad. Pero lo verdaderamente lamentable es que muy pocos conocen siquiera las investigaciones más clásicas sobre la conducta instrumental, es decir, sobre la fabricación y utilización de herramientas, útiles, utensilios o instrumentos, en primates no humanos.

El tópico de nuestra exclusividad en la conducta instrumental fue durante mucho tiempo un límite insalvable que separaba el comportamiento del ser humano y del resto de los animales. En este sentido se entiende la obra clásica de Kenneth P. Oakley (1950), cuyo título Man the tool-maker, recoge una reflexión de Benjamin Franklin por la que el uso y fabricación de herramientas se convertía en la conducta definitoria del ser humano. Hoy sabemos que si bien fue una conducta crítica para nuestro desarrollo como especie animal no fue la única, y también que no se trata de un fenómeno exclusivamente humano pues muy probablemente los antepasados de los homínidos ya fabricaran y utilizaran herramientas, como hacen, por cierto, muchas otras especies animales.

Para acercarnos al tema de nuestra discusión es inevitable recurrir a la ciencia que estudia el comportamiento animal, la etología, una mezcla igualada de biología y psicología (Colmenares 1996); y dentro de ésta a la primatología, disciplina que se encarga de estudiar el comportamiento de los primates, incluyendo en ella tanto al ser humano como a sus ancestros evolutivos más directos. La primatología puede ser de gran utilidad heurística a la hora de reconstruir la prehistoria, aunque proporcionalmente resulta mucho más útil en su aplicación al campo del origen de la humanidad y el primer comportamiento de ésta. Fue éste un aspecto ya percibido por Louis Leakey, patriarca del mayor linaje de prehistoriadores que han investigado el origen de la humanidad, quien durante la segunda mitad del siglo XX encargó y subvencionó sucesivamente varias investigaciones sobre el comportamiento en libertad de los grandes simios para, de este modo, interpretar con una perspectiva más amplia lo que él y su equipo encontraban en los yacimientos paleontológicos africanos y poder crear hipótesis más contrastadas. Éste fue el caso de las investigaciones de Jane Goodall con los chimpancés de Gombe en Tanzania; de Diane Fossey con los gorilas de montaña de Ruanda y el Congo; o de Birute Galdikas con los orangutanes de Borneo. El caso más conocido, sin lugar a dudas, es el de Jane Goodall que se ha convertido en un icono de la ciencia contemporánea.

Gracias a estas investigaciones, entre otras muchas más que veremos más adelante, hemos podido conocer que los primates no humanos ${ }^{1}$ poseen una auténtica cultura material que les permite fabricar y utilizar herramientas con distintos materiales. Pero los descubrimientos no se limitan sólo a la conducta instrumental, sino que mediante estos estudios 
se han podido constatar nuevos límites entre nuestra especie y el resto del mundo animal que, como apuntan muchos autores, tienen que tener un origen evolutivo; es decir, tuvieron que surgir en nuestra filogenia en algún momento de la evolución humana. Tal es el caso, por ejemplo, del llamado "cerebro social", hipótesis que básicamente afirma que el grado mayor de encefalización del ser humano fue una adaptación provocada por sus complejas relaciones sociales, y que se prueba por el hecho de que la encefalización de diferentes grupos de primates está en relación directa con el tamaño de su grupo, como demostraron las investigaciones del antropólogo británico Robin Dunbar (e. g. 1998). Por otro lado, análisis e investigaciones recientes plantean, asimismo, que las relaciones entre pares han desempeñado (y desempeñan) un rol crucial en la sociedad humana y otras sociedades primates (cf. Dunbar y Shultz 2007). Obviamente, este importantísimo rasgo del comportamiento humano hubo de aparecer en algún momento de nuestra evolución, pero su rastreo cronológico conlleva problemas debido a su evidente inmaterialidad. Es por ello que este tipo de investigaciones suelen pasar desapercibidas para los arqueólogos prehistóricos, cuyo trabajo consiste en hallar, analizar e interpretar restos materiales.

Sin embargo, ya hemos señalado que dentro del panorama académico peninsular tampoco las investigaciones respecto a aspectos materiales de los primates no humanos disfrutan de interés y difusión. Para ser sinceros, hemos de reconocer que ese desinterés no refleja necesariamente una aberración particular de la arqueología prehistórica española, ya que investigadores peninsulares de otros campos más afines a la primatología y la etología tampoco se han preocupado de un tema como el de la fabricación y utilización de herramientas en primates no humanos, y los pocos que lo han hecho pueden contarse con los dedos de una mano. Entre ellos, tenemos al único arqueólogo, Jordi Serrallonga (1994, 2005), y los trabajos de algunos etólogos (Call 1996; Sabater Pi 1972, 1974a, 1974b, 1992; Veá y Clemente 1988).

La investigación del uso y fabricación de herramientas en primates no humanos es, no obstante, un tema científico de creciente interés que cuenta con numerosos trabajos publicados en otros países (e. g. Beck 1980; McGrew 1992; Berthelet y Chavaillon 1993, etc.) y produce cada vez más una estrecha colaboración entre distintos campos de la ciencia, como la arqueología prehistórica, la etología, la primatología o la antropología. Este nuevo frente abierto en la ciencia constituye lo que algunos autores han convenido en llamar "Arqueología de los primates" (Haslam et al. 2009), pero que en realidad forma parte de lo que sería una nueva herramienta interdisciplinar, al servicio tanto de la prehistoria como de la primatología, denominada etoarqueología (McGrew et al. 2003; ver una clara definición en Domínguez-Rodrigo 1994).

Lo que tienen en común todos estos trabajos es que utilizan las metodologías de la arqueología y la etología para intentar tomar nuevas perspectivas frente a problemas con los que se enfrentan tanto la primatología como la arqueología prehistórica. A pesar de que la mayoría utilizan la metodología arqueológica para estudiar el comportamiento de chimpancés u otros animales $(i . e$. recogida y examen de materiales, excavaciones de yacimientos, análisis del uso del espacio), todos parecen coincidir en que el estudio del comportamiento material e instrumental de los primates no humanos es un buen marco de trabajo (así como un buen elemento comparativo para la información que se encuentra en los yacimientos prehistóricos) a la hora de intentar reconstruir el comportamiento de los primeros homínidos.

Este es uno de los objetivos que se pretende conseguir en este artículo: plantear la idoneidad de los modelos primatológicos para reconstruir el origen del comportamiento humano; algo, por otro lado, ya apuntado por diversos investigadores (Cleveland et al. 2004; Goodall 1986; McGrew 1992; Pickering y Domínguez-Rodrigo 2010; Wrangham 1987). Otros propósitos son los de transmitir a la investigación prehistórica española una idea clara de lo que significa la conducta instrumental y de contribuir al final, en la medida de lo posible, del mito del Homo faber, todavía persistente a pesar de la intensa crítica de las últimas décadas debido a su poco convincente peso científico (Serrallonga 1994).

\section{2. ¿Qué es la conducta instrumental?}

La conducta instrumental comprende el uso y fabricación de herramientas, dos aspectos relacionados aunque no siempre existen a la vez. Se define como una capacidad cognitiva conectada al conocimiento del mundo físico y a la causalidad (Tomasello y Call 1997), siendo además la forma de manipulación de objetos más compleja que existe en el Reino Animal (Parker y Gibson 1977).

Como fenómeno empírico, la conducta instrumental, al igual que muchos otros comportamientos, implica la dicotomía entre conducta observable y conducta inobservable. Aunque la conducta instrumental puede ser estudiada tanto en lo que atañe a su estructura y su función (procesos observables) como en lo relativo a los mecanismos cognitivos que subyacen en dichos comportamientos (procesos inobservables), el hecho de que dos especies 
distintas o dos individuos de la misma especie utilicen una herramienta con una función equivalente y de una forma similar no implica, ni mucho menos, que los dispositivos cognitivos implicados sean similares. Este artículo se ha construido consultando las investigaciones que se basan en la conducta observable, sin entrar en la citada diferencia, lo que exigiría un espacio muy superior (cf. Griffin 1992 para un buen resumen). El concepto más debatido, sin lugar a dudas, ha sido la del propio uso de herramientas, cuya definición más asentada es la de Beck (1980: 10), aglutinando y complementando las anteriores:

El uso de herramientas es el empleo externo de un objeto ambiental suelto para alterar más eficientemente la forma, posición o condición de otro objeto, otro organismo o el mismo usuario, cuando éste sostiene o lleva la herramienta durante o inmediatamente antes de utilizarla y es responsable de su orientación correcta y efectiva.

Esta definición no reconoce como uso de herramientas, por ejemplo, el comportamiento que llevan a cabo los monos capuchinos (Cebus apella) del parque nacional La Macarena en Colombia, quienes utilizan las juntas de las cañas de bambú (sólidas y resistentes) para golpear contra ellas un fruto de cáscara dura parecido al coco y poder consumir el fruto (Izawa y Mizuno 1977). En este sentido, también se descartaba como uso de herramientas categórico el comportamiento alimentario de las gaviotas en el cual, para poder consumir ciertos moluscos, los dejan caer contra distintas superficies para romper la concha; una conducta que para Beck (1982) encierra una complejidad cognitiva similar a la de la conducta instrumental del chimpancé, pues entre otros aspectos, las gaviotas "calculan" la altura necesaria y "seleccionan" la superficie adecuada sobre la que lanzar los moluscos.

Por ello, dado que la definición anterior no reconocía como uso de herramientas un considerable número de comportamientos que otros tantos investigadores habían observado y en los que estaban implicados objetos que se utilizaban para conseguir un fin, y debido también a nuevas propuestas teóricas (cf. Amant y Horton 2008), Shumaker, Walkup y Beck (2011) han publicado muy recientemente una edición ampliada y actualizada del tratado que el mismo Beck publicó en 1980. Así, en este nuevo catálogo se reconoce también como uso de herramientas (Ibid.: 5-6), aquellos comportamientos en los que el individuo utiliza un objeto fijo o inamovible, pero manipulable, para conseguir una finalidad deseada, ya sea en un contexto trófico o de cualquier otro tipo.

No obstante, según esta nueva definición, las construcciones (tanto de humanos como de otros animales), si bien entrarían dentro de lo que se entiende por cultura material (e. g. Binford 1962: 217-218), no representarían ejemplos de conducta instrumental, como por ejemplo la construcción de nidos en aves y primates (casas o camas para los seres humanos) o las telarañas de los arácnidos. Así pues, una distinción que se ha de tener clara es que la conducta instrumental no es sinónimo de cultura material sino que sería más bien afín al término tecnología; la cultura material, por lo tanto, englobaría a la conducta instrumental. La fabricación de herramientas, por otro lado, no ha sido objeto de tantas y variadas definiciones, ya que se parte del simple axioma de que "cualquier simple modificación de un objeto por el usuario o un conespecífico de tal manera que el objeto funciona más efectivamente como herramienta" (Beck 1980: 11-12) ya es una fabricación. Este argumento puede parecer una visión simplista y endeble de la creación de artefactos, pero es la que manejan los etólogos encargados de estudiar la conducta instrumental; además, la arqueología prehistórica tampoco se ha pronunciado sobre este problema, siquiera proponiendo alguna definición alternativa. En opinión de Beck (Ibid.: 105) existen cuatro modos básicos de fabricación o manufactura de herramientas:

Cuatro modos de fabricar herramientas son reconocidos aquí. El más simple y más común es cortar la conexión fija entre un objeto del entorno y otro (o el sustrato) de manera que el primer objeto puede ser utilizado como herramienta. Este modo es 1lamado detach [separar, quitar, despegar] (...) El segundo modo, subtract [sustraer], consiste en quitar un objeto u objetos de otro objeto suelto de manera que el último puede servir más útilmente como herramienta (...) El tercer modo es add o combine [añadir, mezclar] en el cual dos o más objetos son conectados para producir una herramienta adecuada (...) El último modo de fabricación de herramientas es reshape [reorganizar, dar una forma nueva] y supone la reestructuración fundamental del material para proveer una herramienta funcional

Así, en el momento en que un chimpancé o un orangután arrancan una rama de un árbol y le quitan ramitas y hojas para crear un utensilio, con el cual poder extraer de manera más óptima insectos que se encuentran en los huecos de los árboles o en sus nidos (termiteros, hormigueros, colmenas...), estamos tratando con un modo de fabricación de herramientas mediante detach y subtract. Del mismo modo, la talla de piedra del ser humano y sus antepasados evolutivos más directos se incluiría dentro del modo llamado reshape, que es el más complejo, cognitivamente, de los cuatro. Un ejemplo del tercer modo, add/combine, sería ensamblar dos piezas para alcanzar un objetivo que no puede lograrse con las dos piezas por separado. 
Tanto el uso de herramientas como su fabricación han sido observados en distintas especies animales, y no sólo en los primates y en los mamíferos, hecho que debería remover de nuestro entendimiento definitivamente la imagen del ser humano como único creador y utilizador de herramientas. No obstante, existe una variante del uso de herramientas, el llamado "uso de metaherramientas" (meta-tool use), que, si bien se ha observado en otras especies, parece ser, por ahora, lo que nos separa verdaderamente del resto de los animales en lo que respecta a la conducta instrumental. El uso de metaherramientas sería la utilización de una herramienta para fabricar o alcanzar otra herramienta y, de este modo, poder conseguir la finalidad o meta deseada. Este aspecto representa la infraestructura mental y causal de la tecnología humana, ya que cualquier instrumento, herramienta, útil, artefacto u objeto humano ha sido fabricado utilizando otros tantos, desde los ordenadores y las espadas hasta la cerámica y los bolígrafos pasando por los coches y los botones.

Como hemos dicho, el uso de metaherramientas ha sido observado en otras especies animales, pero en contadísimas ocasiones y siempre en condiciones de laboratorio, nunca en libertad y como parte habitual del repertorio conductual de la especie en cuestión. Tal es el caso del bonobo Kanzi, famoso por haber sido capaz de llevar a cabo una rudimentaria talla lítica con el fin de producir unas lascas que le permitieran cortar una cuerda para poder acceder al premio que contenía una caja (Toth et al. 1993; Schick et al. 1999); o el de unos chimpancés que casualmente descubrieron que podían producir lascas de hueso al golpear éste con una piedra y, de este modo, poder cortar una tapa de acetato de un recipiente y beber un líquido deseado que se encontraba en su interior (Kitahara-Frisch et al. 1987, cit. en Tomasello y Call 1997). El otro ejemplo se ha observado en un ave, el cuervo de Nueva Caledonia, que utilizó un palito para conseguir otro más largo que se encontraba en una jaula, fuera de su alcance, y poder conseguir un trozo de comida que no era accesible con el palo más corto (Taylor et al. 2007).

$\mathrm{Si}$ bien estos tres ejemplos son representativos de que existen rudimentos de uso de metaherramientas en animales no humanos, debemos considerarlos marginales y poco representativos dada su escasez en la literatura científica. La destreza del bonobo Kanzi en la talla lítica, por ejemplo, no supera las capacidades que al respecto podría tener un niño humano de tres años. Sin embargo, la investigación sobre el uso de metaherramientas está comenzando a emerger irremediablemente en etología, y no sería extraño que pronto este auténtico baluarte de la conducta instrumental humana se viera también amenazado.
El origen evolutivo de la conducta instrumental es un aspecto que también ha preocupado a los estudiosos del comportamiento animal. Al hablar de origen evolutivo entendemos que la conducta instrumental no aparece súbitamente en el ser humano o su filogenia más directa, sino que se encuentra presente en otras especies animales, donde su aparición parece responder a unas razones y condiciones similares. De entre todas las hipótesis existentes, son dos las que han cobrado mayor relevancia y las que casi todos los autores suelen citar en sus trabajos. Una, la hipótesis del agonismo (Hall 1963), propone que al manejar herramientas con fines intimidatorios, defensivos u ofensivos, se habría descubierto que dichas herramientas podían utilizarse con otros fines, como el de la alimentación. La hipótesis del forrajeo extractivo (Parker y Gibson 1977), por su parte, nos dice que el origen de la conducta instrumental se encontraría en el hecho de haber tenido que conseguir alimentos que debían de ser extraídos (de agujeros o cáscaras, por ejemplo) y cuya localización espacial y temporal había de ser recordada.

Estas dos hipótesis encajan muy bien si de lo que hablamos es de la conducta instrumental en primates, pero dicen muy poco (o nada) acerca del origen de la conducta instrumental en otro tipo de animales, pues, como hemos señalado anteriormente, existen muchas especies animales que llevan a cabo acciones de uso y/o fabricación de herramientas, a pesar de ser una conducta que es una extrañeza taxonómica (Chappell y Kacelnik 2002).

Bajo este prisma conceptual, la conducta instrumental ha sido observada en varias clases de animales no humanos, y no solo en los primates. Las hormigas, por ejemplo, utilizan partículas de arena para absorber miel y poder llevárselas al hormiguero con el fin de consumirlas o almacenarlas (Barber et al. 1989; ver Fig. 1). La conducta instrumental se ha observado también en otros invertebrados, como los cefalópodos; así, la especie Amphioctopus marginatus utiliza cáscaras de coco para protegerse frente a posibles depredadores (Finn et al. 2009, ver Fig. 2). En cuanto a los peces, tradicionalmente sólo se solía nombrar al pez arquero (Toxotes jaculatrix) como utilizador de herramientas, ya que se vale del agua como proyectil con el que derribar a sus presas (Beck 1980); no obstante, las observaciones sobre conducta instrumental en peces se han ampliado en los últimos años: el comportamiento predador del pez arquero se ha observado experimentalmente en otras especies como Potamotrigon caxtesi, más conocida como raya (Byrne, Burghardt y Kuba 2010), o Colisa chuna, lanzan almejas contras las rocas para romper su cascarón y consumir el recurso cárnico (Bernardi 2011). Las aves son, asimismo, muy diestras a la hora de fabricar y utilizar herramientas; 

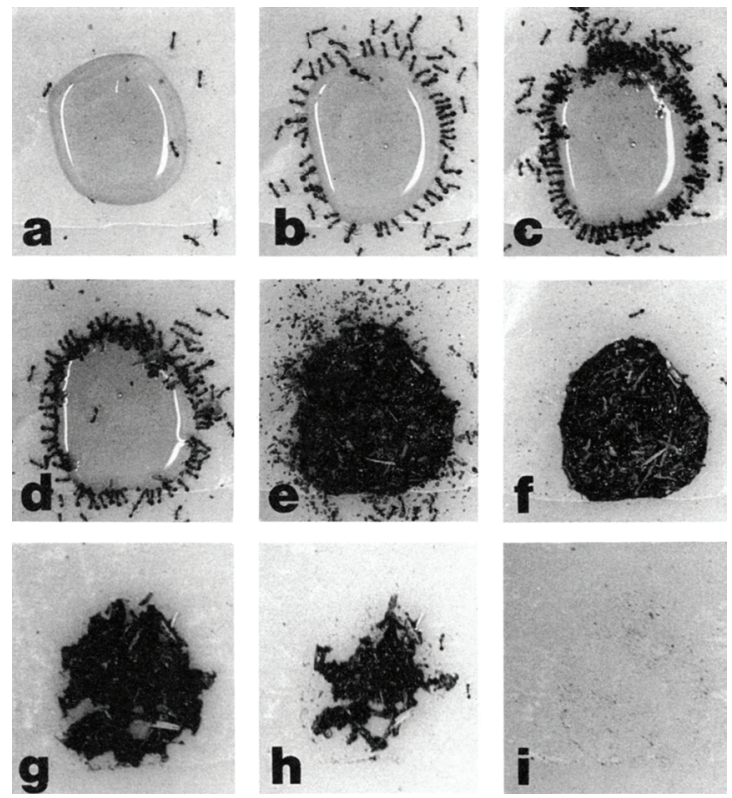

Figura 1.- Secuencia de unas hormigas haciendo uso de partículas de arena para transportar miel (según Barber et al. 1989).

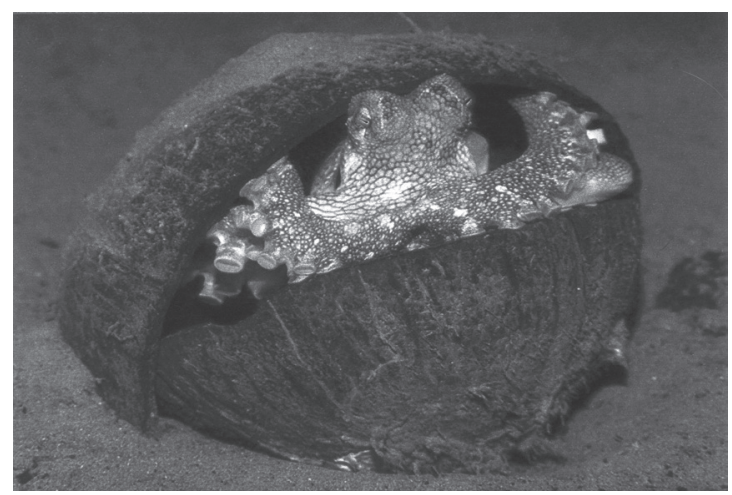

Figura 2.- Amphioctopus marginatus y su particular "casco" (según Finn et al. 2009).

en este sentido es muy conocido el caso del pinzón de las Galápagos, que modifica y utiliza espinas de cactus y ramitas para depredar sobre distintos tipos de insectos, seleccionando además la longitud adecuada (Tebbich y Bshary 2004). Y, por supuesto, la conducta instrumental se ha constatado también en mamíferos como el elefante asiático, que utiliza ramas modificadas por él mismo como matamoscas, evitando así las constantes picaduras de este insecto, que pueden provocar una pérdida considerable de sangre (Hart et al. 2001; ver Fig. 3). Estos ejemplos son sólo algunos de los muchos que existen en la literatura científica, por eso creemos que son necesarias nuevas hipótesis que amplíen el origen de la conducta instrumental más allá de los primates.
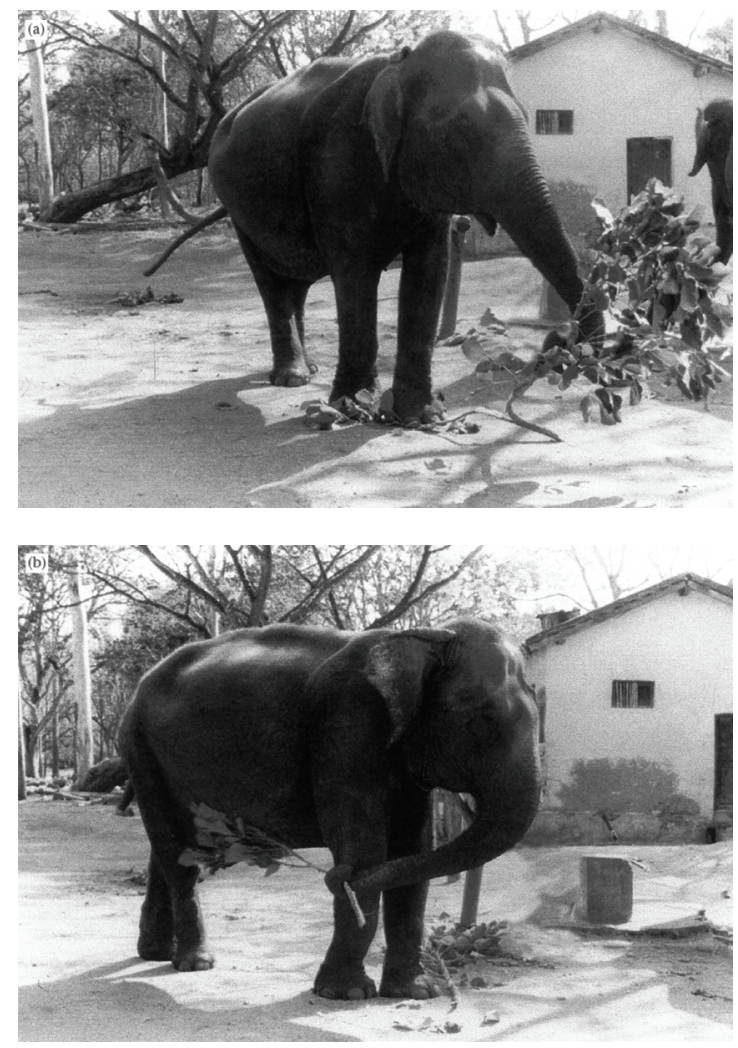

Figura 3.- Un elefante asiático utiliza ramas con hojas para espantar a los mosquitos (según Hart et al. 2001).

\section{Conducta instrumental en primates no humanos: algunos ejemplos ilustrativos}

Las referencias existentes en la literatura científica sobre la conducta instrumental de los primates no humanos son numerosísimas. Es por ello que para la redacción de este epígrafe se debió hacer una selectiva criba para escoger aquellas que representaran el mejor ejemplo para los profanos en la materia. Respecto a la taxonomía utilizada, seguiremos la propuesta por Boyd y Silk (2009: 123) en la que dentro del orden de los Primates se distinguen dos subórdenes: Prosimios y Antropoides. Los Prosimios, a su vez, se dividen en tres infraórdenes (Lemuriformes, Lorisiformes Tarsiformes) y tres superfamilias (Lemuroidea, Lorisoidea y Tarsiodea). Por su parte, los Antropoides constan de dos infraórdenes (Platyrrhini [platirrinos] y Catarrhini [catarrinos]) y tres superfamilias (Ceboidea [monos del Nuevo Mundo], Cercopithecoidea [monos del Viejo Mundo] y Hominoidea [simios antropomorfos y humanos]). La superfamilia de los Hominoidea incluye tres fa- 
milias: Hylobatidae (simios menores, como gibón y siamang), Pongidae (grandes simios: orangután, gorila, bonobo y chimpancé) y Hominidae (filogenia humana; sobre esta familia, véase el apartado 3.4). En este sentido, debemos aclarar que el título de alguno de los subapartados de este epígrafe no hace referencia a la totalidad del grupo taxonómico sino sólo a aquellos en los que se ha observado conducta instrumental. Así, el subapartado "3.3" no indica que los cercopitecinos sean los únicos primates del Viejo Mundo, sino que es el grupo en el que se ha observado conducta instrumental. Hemos creído necesario hacer esta aclaración para evitar confusiones mayores.

\section{1. Prosimios}

En primer lugar debemos comenzar por el suborden de los Prosimios. Se trata de un grupo en el que perviven muchos de los rasgos físicos y conductuales de los primeros primates, lo que hace que tengan muchas características en común con otros mamíferos; tal es así que una especie de roedor, Tupaia glis, fue considerada dentro de este grupo hasta la década de 1980 (Rowe 1996). No obstante, pese a este tipo de desavenencias taxonómicas puntuales, la relación filogenética de los Prosimios con el resto de primates es indudable.

Las evidencias sobre conducta instrumental en este grupo son ínfimas. En libertad no se ha observado nunca un uso o fabricación de herramientas, ni siquiera a título anecdótico. No obstante, en una investigación llevada a cabo en cautividad (Santos et al. 2005), se ha comprobado que algunos individuos de la especie Lemur catta (el lémur de cola anillada) y de la especie Eulemur fulvus (el lémur marrón) son capaces de utilizar distintas herramientas para alcanzar y arrastrar pedazos de comida que se encuentran fuera de su alcance, en el tipo de experimentos conocidos como out-of-reach problem. En el experimento, se comprobó también que los individuos eran capaces de seleccionar la funcionalidad apropiada de la herramienta, ya que se les daba a escoger entre dos, una de las cuales era menos efectiva (o directamente inútil) a la hora de alcanzar el objetivo.

\section{2. Antropoides: el Nuevo Mundo (calitrícidos y cébidos)}

Ya en el grupo de los Antropoides, nos encontramos con una amplia variedad de conductas instrumentales en diferentes contextos, aunque su presencia varía según el taxón que tratemos. En los monos del Nuevo Mundo (platirrinos o ceboideos) los calitrícidos, grupo taxonómico al que pertenecen los errónea y comercialmente denominados monos titís (los auténticos monos titís pertenecen al grupo de los cébidos), y para los que apenas existen referencias, reportaron una reseñable conducta observada por Stoinski y Beck (2001). Estos investigadores fueron testigos de cómo varios individuos de la especie Leontopithecus rosalia rosalia -a los que se había dejado en aparente libertad dentro de un zoológico debido a que iban a ser reintroducidos a la vida salvaje - utilizaban pequeñas ramitas, así como el collar que se les había colocado como localizador, para inspeccionar grietas y huecos en los árboles (presumiblemente en busca de alimento) y para acicalar a miembros del grupo, entendiéndose estas conductas dentro de los contextos trófico y del aseo/bienestar.

Pero, sin lugar a dudas, el género más importante de los monos del Nuevo Mundo en cuanto a conducta instrumental se refiere, es el del mono capuchino (Cebus sp.), del grupo de los cébidos, que ha conseguido igualar a los grandes simios en cuanto al interés que suscita su comportamiento en el campo del uso y fabricación de herramientas. No por casualidad, un sobrenombre muy difundido para este tipo de primates es el de los "chimpancés del Nuevo Mundo", dado el alto nivel de inteligencia que presentan y que les ha llevado a ser utilizados en programas de ayuda a humanos parapléjicos y tetrapléjicos, sirviéndoles de ayuda en las tareas más rutinarias (acercarles pajitas para beber agua, pasarles las páginas de los libros, ponerles música, encender el contestador telefónico para escuchar los mensajes...). La monografía más completa que existe sobre este género de primates es la de Fragaszy, Visalberghi y Fedigan (2004), donde se dedica un capítulo entero a su conducta instrumental, aunque la obra queda algo obsoleta al no recoger algunas de las más recientes investigaciones que se han llevado a cabo.

Cabe decir que la conducta instrumental del mono capuchino se ha observado en diferentes contextos, como pueden ser el agonístico, el del aseo/bienestar o el trófico. Boinski (1988) presenció cómo un individuo de la especie Cebus capucinus utilizó un palo para golpear repetidas veces a una serpiente hasta que consiguió dejarla sin vida. En su monografía, Beck (1980) refiere varios casos de uso de herramientas con fines de limpieza, como utilizar hojas y ramitas para deshacerse de sustancias molestas (barro o restos de comida).

Sin embargo, es la fabricación y uso de herramientas en contextos tróficos la que ha ofrecido una mayor complejidad conductual a este respecto 
en este tipo de primates. La primera vez que se observó esta habilidad fue en experimentos llevados a cabo en condiciones de cautividad y de laboratorio, para descubrirse después en poblaciones en libertad. En este sentido, tenemos que destacar las investigaciones llevadas a cabo por Westergaard y Suomi (1993, 1994a, 1994b, 1994c). En un experimento quisieron comprobar la capacidad de individuos de la especie Cebus apella para fabricar y utilizar herramientas de piedra (Ibid. 1994c). Para ello, facilitaron a 11 individuos 7 piedras de cuarcita (una de ellas visiblemente más grande que el resto para que pudiera ser utilizada como yunque), de las cuales había que extraer lascas que permitieran cortar la tapa de acetato de un recipiente y poder alcanzar el objetivo (un alimento); 6 de los 11 individuos consiguieron crear las lascas en la primera parte del experimento mediante distintos métodos (golpeándolas contra la piedra yunque; colocando la piedra en otro objeto y golpeándola con otra piedra; o golpeando una piedra contra otra). Posteriormente, en la segunda parte del experimento, 3 individuos de 15 consiguieron utilizar exitosamente las lascas para cortar la tapa de acetato y acceder a la recompensa. Este experimento amplió la información anterior que se tenía acerca de la conducta instrumental del mono capuchino, que había sido observado ejecutando distintos tipos de comportamientos como utilizar piedras, huesos, espigas, ramas y toallitas de papel (en casi todos los casos modificados antes de su uso) para acceder y conseguir distintos tipos de alimentos que no eran asibles con sus propias manos (Westergaard y Fragaszy 1987; Westergaard y Suomi 1993, 1994a). Además, en una ocasión se analizaron también las marcas de corte dejadas por el uso de las lascas sobre huesos, mostrando que podrían llegar a confundirse con improntas antrópicas (Westergaard y Suomi, 1994b).

Más importantes parecen las últimas investigaciones sobre la conducta instrumental de estos primates, a través de las cuales hemos podido saber que las poblaciones en libertad de la especie Cebus libidinosus que habitan en Boa Vista (Brasil) utilizan piedras y yunques para romper la dura cáscara de algunos frutos que les impide acceder a la parte comestible, la cual es una buena fuente nutritiva (Fragaszy et al. 2004). Incluso sabemos que seleccionan piedras de tamaño y peso apropiado para llevar a cabo esta actividad y que las transportan desde distancias considerables hasta los yunques (Visalberghi et al. 2007, 2009). Esta conducta ha sido observada tanto directa como arqueológicamente, analizando las muescas que los golpes dejan en las piedras y troncos utilizados como yunques (Figs. 4 y 5 ).

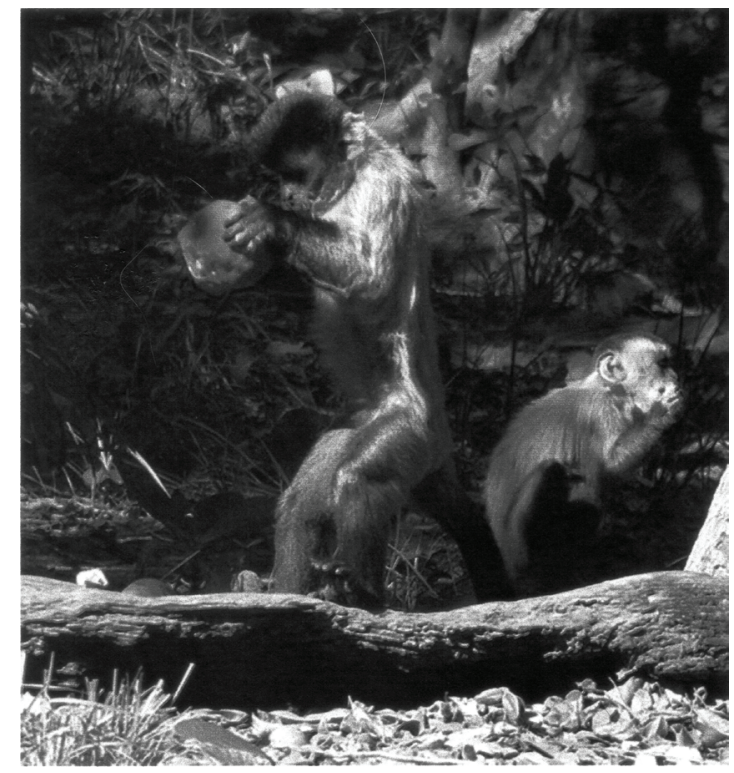

Figura 4.- Un mono capuchino adulto utilizando una piedra para romper la cáscara de un fruto (según Visalberghi et al. 2007).

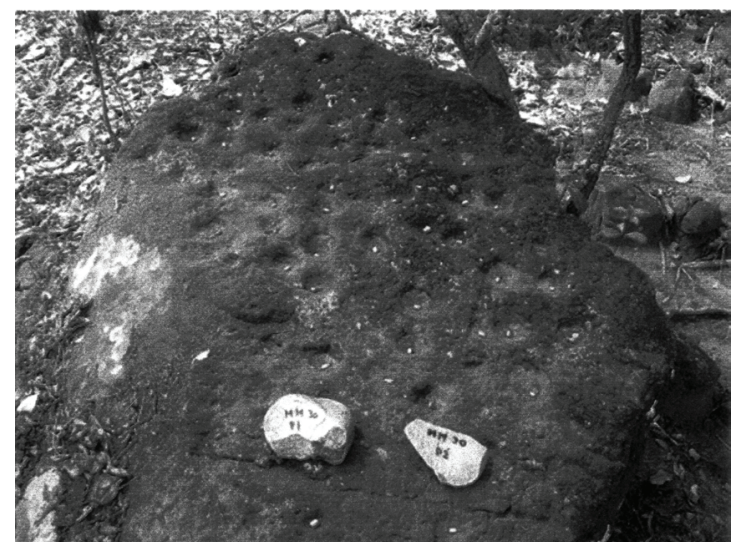

Figura 5.- Trazas de uso producidas por la conducta percutora del mono capuchino en un "yunque" de piedra (según Visalberghi et al. 2007).

Lo llamativo de estas investigaciones es que han puesto de relieve la capacidad de los monos capuchinos de llevar a cabo un comportamiento que, por su complejidad, se entendía hasta hace poco como una capacidad exclusiva de los chimpancés y los homínidos (incluyendo al ser humano). Con ello volvemos a la idea de que la conducta instrumental no puede ser observada más como un símbolo conductual exclusivo del ser humano y sus antepasados más directos, sino que es un comportamiento presente ya en los primates desde estadios filogenéticos muy tempranos, pues los monos capu- 
chinos llevan evolucionando independientemente de los grandes simios desde hace $40 \mathrm{~m}$. a.

\subsection{Antropoides: el Viejo Mundo (cercopitecinos)}

Los cercopitecinos son una subfamilia de primates que forman parte de los monos del Viejo Mundo o cercopitecoideos y que está compuesta por los babuinos o papiones, los macacos y los monos verdes. Tanto los cercopitecinos como el resto de cercopitecoideos (colobinos y cercopitecos) comparten con los póngidos (grandes simios) la característica de poseer una nariz cuyos orificios nasales miran hacia abajo y que, además, están separados por un estrecho tabique nasal, lo que les da a todos ellos la denominación de catarrhini, rasgo que los distingue de los platyrrhini o monos del Nuevo Mundo, cuya nariz es achatada y con orificios laterales. Se encuentran tanto en África como en Asia, existiendo una sola especie en territorio europeo, el macaco de Berbería, erróneamente denominado como macaco de Gibraltar.

Las especies cuya conducta instrumental merece ser destacada son los macacos (Macaca $s p$.) y los papiones o babuinos (Papio $s p$.). Dentro de los macacos, una hembra de la especie Macaca radiata fue observada en libertad fabricando una herramienta que fue utilizada para calmar los síntomas que le producía una irritación en su zona vaginal (Sinha 1997). En el contexto trófico, ya Carpenter (1887) observó a un individuo en libertad de la especie Macaca fascicularis utilizar una piedra para abrir la concha de una ostra y consumir la parte comestible. Del mismo modo, Tokida y colaboradores (1994) diseñaron un experimento que se llevó a cabo en libertad para saber si los individuos de un grupo de macacos japoneses (Macaca fuscata) eran capaces de extraer manzanas de un tubo ayudándose para ello de piedras. Muy pocos lograron conseguirlo, pero los que lo hicieron fueron además innovadores metodológicos, ya que una hembra utilizó como herramienta a su propia cría, a la cual introducía en el tubo para que le sacara el premio alimenticio.

Respecto a los papiones, merecen ser destacadas, sobre todo, las investigaciones realizadas por Beck $(1972,1973)$ con la especie Papio hamadryas hamadryas dentro del contexto trófico y en condiciones de cautividad y laboratorio. En la primera de ellas, la de 1972, ideó una situación experimental en la que el individuo en cuestión debía de utilizar una cadena para arrastrar una cacerola que contenía comida cerca de la jaula en la que se hallaban él y los miembros de su grupo, algo que consiguió sin muchos problemas. Más revelador respecto a las capacidades de esta especie fue el experimento de 1973, el cual demandaba para su correcta resolución la cooperación entre va- rios individuos. Para ello, creó un diseño experimental por el cual un sujeto que se encontraba en una jaula tenía que acercar un recipiente con comida con la ayuda de una herramienta (una vara); el problema era que la herramienta se encontraba en un habitáculo adyacente al que no podía acceder. La correcta resolución del problema requería que la herramienta fuese trasladada por otro individuo de la jaula de al lado hasta una posición que permitiera al sujeto de la primera jaula cogerla y traspasarla a su habitáculo, utilizándola entonces para acercar el recipiente con comida y poder consumirla. El experimento tuvo éxito, y demostró que los babuinos tenían la capacidad de utilizar herramientas de un modo cooperativo y sin entrenamiento previo, lo cual hasta entonces sólo había sido observado en chimpancés (y humanos, obviamente). Esto hizo comprender que muchas de las conductas que se observan en los grandes simios pueden existir también en otras especies de primates, estrechándose en algunos aspectos lo que antes era una amplia barrera conductual entre los grandes simios y el resto de antropoides.

\section{4. Antropoides: el Viejo Mundo (hominoideos)}

Los hominoideos son un grupo de primates formado por los hilobátidos (o simios menores), los póngidos (o grandes simios: orangután, gorila, chimpancé y bonobo) y el cladograma evolutivo del ser humano, es decir, los homínidos o primates huma$\operatorname{nos}^{2}$. Dentro de él, encontramos a nuestros parientes biológicos más cercanos, tanto conductual como genéticamente, empezando a separarse nuestra filogenia respecto a la suya hace unos $20 \mathrm{~m}$. a., fecha en la que vivió nuestro último antepasado común. Los estudios realizados con ellos no se han limitado sólo a la conducta instrumental, sino que han tocado muchos otros aspectos, como organización social, sexualidad o cognición, encontrando casi siempre una salida comparativa con nuestra especie.

Los hilobátidos son el amplio número de especies de gibón, el cual se distribuye demográficamente por el sudeste asiático. Pese a tratarse de una especie muy emparentada con la nuestra, las referencias respecto a su conducta instrumental son limitadas. Aparte de utilizar ciertos objetos con finalidades intimidatorias, algo común a todos los simios (Beck 1980), sólo han sido observados utilizando herramientas en un experimento llevado a cabo en cautividad con la especie Bunopithecus hoolock (Cunningham et al. 2006), por el cual demostraron tener el potencial cognitivo para utilizar un rastrillo con la finalidad de acercar una comida que estaba fuera de su alcance, aunque hay que destacar que lo hicieron de un modo auténticamente espontáneo, sin ningún tipo de instrucción 
previa. Más recientemente, Geissmann (2009) observó en cautividad cómo una hembra de la especie Hylobates har utilizaba una puerta corrediza para incrementar el clímax acústico de las vocalizaciones ("grandes llamadas") que lanza en respuesta a los alardes sonoros que emiten los machos.

Aparte de nuestra especie y nuestros antepasados más directos, el grupo de los grandes simios lo componen los orangutanes, gorilas, bonobos y chimpancés. Exceptuando al gorila, se ha observado en este grupo una habilidad superior respecto al resto de primates en el uso y fabricación de herramientas, constituyendo el chimpancé la especie más estudiada al respecto.

Los orangutanes (Pongo sp.) representaban hasta hace pocos años un enigma respecto a la conducta instrumental. Se sabía que eran capaces de utilizar y fabricar herramientas de un modo muy complejo en cautividad o semicautividad, como colocar cajas verticalmente o ensamblar dos piezas para alcanzar un objetivo. Sin embargo, en libertad era prácticamente nula la información que se tenía al respecto. Los investigadores trataban de explicar este hecho aduciendo su gran corpulencia, así como su escasa sociabilidad y estilo de vida arborícola (Galdikas 1982; Lethmate 1982).

Así, hasta 1996 no se publicaron las primeras observaciones sobre conducta instrumental de orangutanes en libertad, descubriéndose entonces que el papel de esta conducta dentro de ellos tenía una importancia similar, tanto para su rutina eco- lógica como en la calidad de la misma, a la que adquiere en la sociedad del chimpancé. Pero como hemos dicho, ya en condiciones de cautividad el orangután había demostrado poseer la inteligencia necesaria para utilizar sin problemas herramientas, muchas veces en pruebas muy complejas. Por ejemplo, en individuos cautivos reintroducidos a la vida salvaje de la especie Pongo pygmaeus, Galdikas (1982) observó que cuando trasladaban a los individuos desde su zona libre hasta la estación de alimentación, para lo que había que cruzar un río, éstos lograban escabullirse, se acercaban a las canoas del grupo investigador, desataban los nudos que las amarraban y se marchaban en ellas para disfrutar de auténticos "viajes placenteros", para lo que utilizaban, además, palos a modo de remos. En otra ocasión, un sujeto de la misma especie logró resolver sobradamente un problema realmente complejo. Primero debía elegir una llave apropiada; ya con la llave correcta, al individuo se le presentaban cuatro cajas, de las cuales una estaba vacía, otra contenía el premio (un zumo), y las otras dos contenían cada una otra llave, de las que sólo una era la que podía abrir la caja del zumo (Fig. 6). Los resultados fueron sorprendentes, ya que de 400 ensayos el individuo resolvió correctamente 312 , lo que equivale a un $80 \%$ de acierto (Lethmate 1982).

Por estudios como los señalados, sorprendía que los orangutanes no utilizasen o fabricasen herramientas en libertad, hasta que Van Schaik et al.

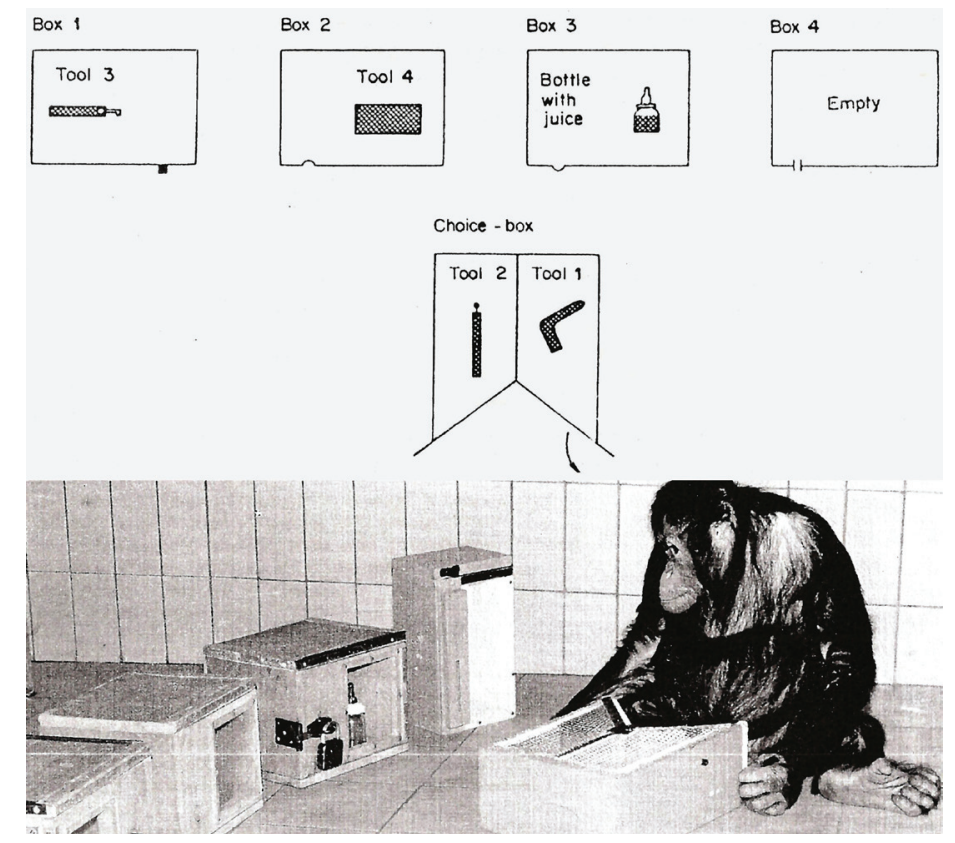

Figura 6.- Ilustración sobre el esquema del experimento de las cajas que un orangután logró resolver e imagen del mismo (según Lethmate 1982). 
(1996) publicaron las observaciones y datos que habían recogido en una población de la especie Pongo abelii en Suaq Balimbing (Sumatra, Indonesia), por las que hemos podido saber que los orangutanes poseen una cultura material usada en el forrajeo sobre insectos y otros alimentos, algo que hasta ese momento sólo se había observado en chimpancés. Estos orangutanes arrancan ramas de los árboles y las procesan para convertirlas en herramientas más eficaces; de ellas, se extraen hojas, ramitas y corteza con manos y dientes. Con estas herramientas, recogen hormigas, termitas, abejas y miel de los agujeros de los árboles o de colmenas, y también extraen las semillas comestibles de la fruta Neesia $s p$., ya que se encuentran embebidas $\mathrm{y}$ rodeadas de un molesto vello. Además realizan una selección, ya que son las ramas de mayor anchura y longitud las empleadas para el forrajeo sobre insectos. Asimismo, a las herramientas utilizadas para la extracción de las semillas se les despoja siempre de la corteza. A este estudio se debe que el orangután forme junto al mono capuchino y al chimpancé la tríada taxonómica por excelencia de la conducta instrumental.

El gorila (Gorilla sp.) ha sido observado en libertad tan sólo en una ocasión llevando a cabo un comportamiento que incluyera algún tipo de útil (Breuer et al. 2005). En este estudio se pudo filmar y fotografiar cómo un sujeto de la especie Gorilla gorilla gorilla, utilizó una rama a modo de sonda para comprobar la profundidad del terreno pantanoso sobre el que se estaba desplazando. Aparte de este trabajo, no existe nada más respecto a su conducta instrumental en libertad, lo cual ha dado lugar a diversas explicaciones, ya que es bien conocida la gran inteligencia que poseen los gorilas (cf. Gómez 1989). Una de estas explicaciones fue propuesta ya por Parker y Gibson (1977) y afirma que los gorilas utilizarían su imponente poderío físico para conseguir recursos alimenticios que otras especies obtienen mediante la conducta instrumental; es decir, que con sus puños abrirían termiteros y romperían la dura cáscara que presentan algunos frutos en vez de fabricar y utilizar herramientas para conseguirlo. Esta explicación parece plausible, sobre todo teniendo en cuenta que el gorila ha demostrado, en cautividad, poseer potencial cognitivo suficiente para utilizar herramientas a la hora de obtener alimentos que han de ser extraídos (Pouydebat et al. 2005), lo que concuerda con la posibilidad de que en libertad no utilicen herramientas porque no le son necesarias.

A los bonobos (Pan paniscus) y a los chimpancés (Pan troglodytes sp.) a veces se les denomina como pánidos, un término muy cómodo lingüísticamente (ya que agrupa a dos especies distintas y varias subespecies) pero que carece de validez taxonómica. Sobre el bonobo, ya citamos una de las investigaciones más famosas que existen sobre la conducta instrumental en la arqueología experimental (o etoarqueología si se prefiere), como son las investigaciones llevadas a cabo con Kanzi y su talla lítica (Schick et al. 1999; Toth et al. 1993). De ellas se deduce la diferencia respecto de la industria lítica de los primeros homínidos, que respondía a un esquema mental previo, al contrario que en el caso de Kanzi, que si bien inventó un método propio de obtener lascas (lanzando el núcleo contra el pavimento de las instalaciones), parecía actuar por la estrategia de "ensayo y error". Además, hay que tener en cuenta que sus habilidades no superaban las que podría tener un niño de tres años y, también, que se trataba de un alumno aventajado, pues su inteligencia superaba con creces la de sus compañeros (Savage-Rumbaugh y Lewin 1994).

Es también llamativo que el bonobo no utiliza ni fabrica herramientas en libertad como parte de sus conductas regulares, pues sólo existe una referencia al respecto (Kano 1982), en la cual se observó a algunos individuos de la región de Wamba (República Democrática del Congo) utilizar ramas pobladas de hojas a modo de paraguas para protegerse de la lluvia, aunque el mismo autor pone en duda que la herramienta sea realmente eficaz respecto a su objetivo.

Finalmente, llegamos al primate cuya conducta instrumental es la más regular, variada y compleja, tanto en cautividad como en libertad, y tanto en observaciones espontáneas como en la superación de pruebas experimentales: el chimpancé. Tal es así que McGrew $(1992 ; 1993)$ no duda en nombrarla como la especie cuya conducta instrumental es indudablemente inteligente y la que posee una genuina cultura material.

Empezando por el contexto agonístico y de aseo/ bienestar, citar todas las referencias existentes sería aumentar en exceso la bibliografía de este trabajo; aparte de lo publicado, puedo decir que yo mismo he sido objetivo de piedras lanzadas por chimpancés. Un ejemplo bien conocido es el relatado por Jane Goodall (1986). En él, Mike, un sujeto que ocupaba uno de los puestos más bajos en la jerarquía social del grupo, logró convertirse en macho dominante mediante el uso de latas de parafina, con las que consiguió amedrentar a los anteriores cabecillas mediante ataques y/o alardes agonísticos. La misma Goodall (1964) presenció también cómo los chimpancés de Gombe (Tanzania) utilizan normalmente hojas a modo de papel higiénico para limpiarse después de orinar o defecar, o bien para deshacerse de sustancias molestas como barro o restos de comida. 
El contexto trófico es el que ha generado, sin lugar a dudas, la mayor cantidad de información respecto a la conducta instrumental del chimpancé. A si, conocemos muy bien tanto el forrajeo de insectos como el procesamiento de frutos con cáscara dura que lleva a cabo esta especie ayudándose de herramientas fabricadas por ellos mismos. La utilización de herramientas para obtener hormigas fue observada por primera vez en cautividad por Köhler (1989) en La Casa Amarilla de Tenerife, lugar en el que este padre de la primatología llevó a cabo sus más famosas investigaciones. Después de él, fue Goodall la que popularizó esta conducta, siguiéndole muchos otros investigadores, conociéndose en la actualidad como pesca y/o recogida de termitas y hormigas (e. g. Boesch y Boesch 1990; Teleki 1974; Nishida 1973). El procedimiento consiste en que los chimpancés se hacen con una materia prima (ramas, ramitas, peciolos de hojas, briznas gruesas de hierba...) y la transforman con manos y dientes hasta obtener la forma deseada, para dirigirse o bien a un termitero y hormiguero o a otros lugares (como el propio suelo o huecos en troncos caídos) y utilizan la herramienta fabricada para provocar que los insectos comiencen a invadirla, momento en el cual son consumidos. Las técnicas para engullirlos son o bien depositarlos directamente en la boca, o bien recogerlos en una mano y pasarlos de ésta a la boca. Herramientas similares son también utilizadas para obtener larvas de abeja o miel (Boesch y Boesch 1990).

Otra conducta trófica de especial relevancia es el uso de piedras y bastones de madera para romper la cáscara dura que presentan algunos frutos (Fig. 7), apoyándose en yunques de piedra o madera, y poder consumir el recurso alimenticio del interior (Boesch y Boesch 1990). Se trata ésta de una conducta compleja, que sólo ha sido observada en otra especie de primate (el mono capuchino) aunque en el chimpancé es una actividad más compleja si cabe, pues seleccionan piedra o madera dependiendo de la dureza de la cáscara (Boesch y Boesch 1983). Además, crean mapas mentales con los que manejar el espacio en el que se mueven y optimizar el comportamiento, acercando las piedras a los lugares más cercanos donde hay frutos, o llevando los frutos a los lugares más cercanos con piedras, aparte de seleccionar las piedras más ligeras cuando la distancia hasta el fruto se incrementa (Boesch y Boesch 1984).

En el mismo sentido de procurarse recursos alimenticios, se ha observado por primera vez cómo un chimpancé utiliza una herramienta en la caza. Es conocida la costumbre de los chimpancés de consumir carne, para lo que suelen cazar a presas de pequeño tamaño, pero nunca se había tenido noticia de

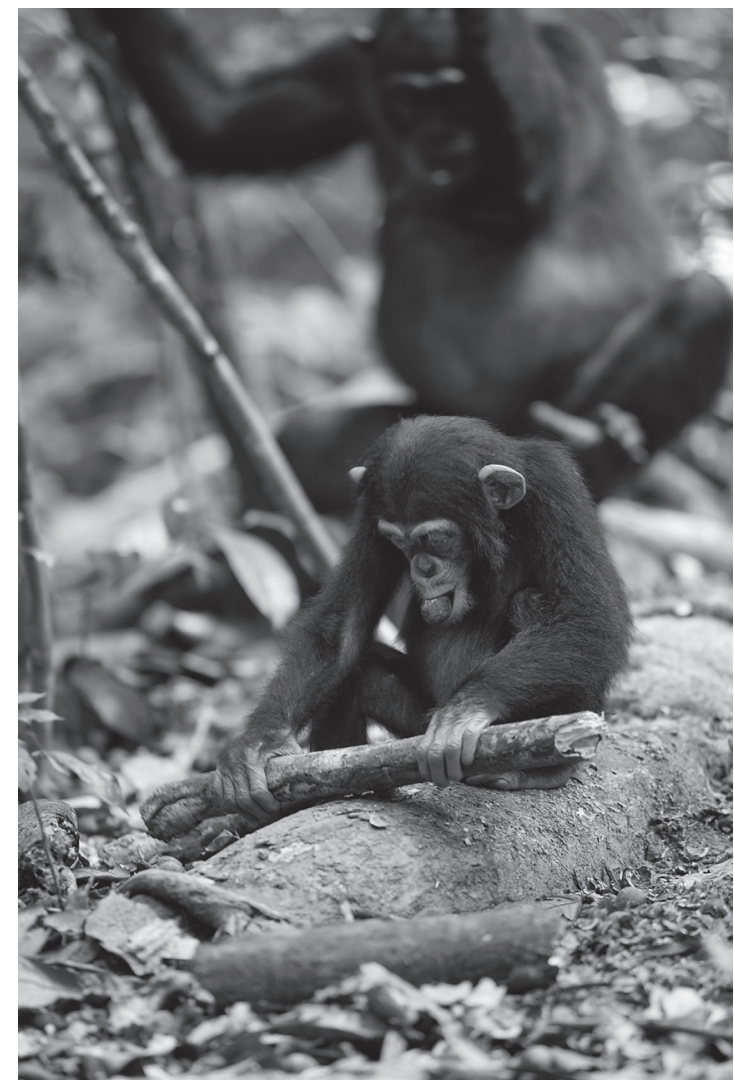

Figura 7.- Cría de chimpancé rompiendo la cáscara de los frutos con un "martillo" de madera sobre "yunque" de madera (Disneynature's).

que utilizasen herramientas para ello. Sin embargo, Pruetz y Bertolani (2007) observaron a un chimpancé utilizar una rama, la cual había sido transformada para su utilización, para pinchar e intimidar a un gálago (un pequeño prosimio), que se encontraba escondido en el agujero de un árbol, y provocar que saliera de su escondrijo y poder consumirlo.

Por último, tenemos que referirnos a un tipo de comportamiento que llama mucho la atención, como es el "alarde del recorte de hojas" (leaf clipping display). En esta conducta, el chimpancé coge una hoja y comienza a mordisquearla produciendo un sonido característico, algo que sólo hace en determinadas ocasiones sociales. De este modo, la herramienta es utilizada por machos adultos frente a una hembra en estro como muestra de posesión; por machos adolescentes frente a hembras como muestra de cortejo; por hembras en estro frente a machos adolescentes como solicitud de cópula; o por machos y hembras frente a observadores humanos como solicitud de comida (Nishida 1980). Las características de este comportamiento han llevado a algunos autores a considerarlo como actividad ritual (McGrew 1993). 
En este sentido, el tema sobre la cultura en animales no humanos está cobrando cada día más fuerza, haciendo que antropólogos, psicólogos, biólogos y etólogos intenten ponerse de acuerdo para definir este auténtico bastión del comportamiento humano, debate que queda fuera de los límites de este trabajo, pues requeriría ser tratado en exclusividad. Pero debemos señalar que el chimpancé es un animal cultural, pues existen evidentes diferencias entre las distintas poblaciones de esta especie, no ya sólo en la conducta instrumental sino también en la social. Un claro ejemplo lo constituye el hecho de la conducta percutora se da sólo en las poblaciones de chimpancés del oeste de África, en la subespecie Pan troglodytes verus, mientras que para los chimpancés del este y centro de África es una actividad desconocida, a pesar de que tienen disponibles tanto la materia prima como los frutos. Diferencias similares se dan también en otros muchos comportamientos, como el forrajeo sobre insectos o distintas formas de espulgarse ( $c f$. Boesch 2003; Whiten et al. 2001). Este tipo de investigaciones están amenazando lo que para muchos es el verdadero límite entre el ser humano y el resto de especies animales: la cultura.

\section{Conclusiones}

¿Por qué y cómo nos puede ayudar el estudio de la conducta instrumental en primates no humanos a reconstruir la prehistoria? La respuesta a esta pregunta es muy sencilla: los primates son nuestros parientes biológicos más cercanos, y la conducta instrumental es un rasgo crítico en la evolución del comportamiento humano (aunque no el único). Además, dentro de los primates tenemos que los grandes simios, en general, y los chimpancés, en particular - dado que de todos los primates son los más cercanos a nuestra especie- podrían representar la condición plesiomórfica de los humanos, tanto por su morfología como por su comportamiento (Pickering y Domínguez-Rodrigo 2010).

Así, los estudios con primates no humanos permitirían llevar a cabo estudios basados en el principio de analogía de un modo similar a como se hace en etnoarqueología ( $c f$. Hernando 1995); aunque su aplicación estaría limitada a la arqueología sobre el origen de la humanidad. Beck (1980: 215-231) ya lo apuntó al decir que "dado que el comportamiento de los animales extintos no es observable, su estudio es necesariamente inferencial". Tenemos que señalar, también, que no cualquier tipo de analogía es válida. Pickering y Domínguez-Rodrigo (2010) han profundizado en la utilización de los modelos de chimpancé para reconstruir el comportamiento humano, exponiendo que existen dos tipos de analogía: formal y estructural. La analogía formal simplemente transcribe una observación del presente hacia el pasado, mientras que la analogía estructural produce inferencias realizadas por un razonamiento analógico, donde tras identificar un comportamiento éste es medido y comparado con los datos que ha ido acumulando la paleoantropología.

Un ejemplo de analogía formal sería la afirmación de que las hembras de los primeros homínidos serían las que fabricaran y utilizaran herramientas con mayor frecuencia, ya que es sabido que las hembras de chimpancé observan más la conducta instrumental que los machos (Boesch \& Boesch,1981; McGrew, 1992). No existe aquí un razonamiento analógico, aunque la idea sea muy atractiva y desafiante.

En el caso de proponer que los primeros homínidos utilizaran y fabricaran herramientas en contextos similares en los que lo hacen los primates no humanos (agonismo, aseo/bienestar, forrajeo sobre insectos y vegetales), algo que parece aceptado por la comunidad científica (McGrew 1992), estaríamos ante una analogía estructural, pues podríamos medir y comparar los datos de la primatología con los que tiene la paleoantropología y la antropología, respectivamente, para los primeros homínidos y para poblaciones humanas tradicionales. Sin embargo, en el caso de la analogía formal señalada nos sería imposible comparar un hecho como es el que las hembras de los primeros homínidos fueran las que fabricaran y utilizaran herramientas, ya que no deja ningún tipo de prueba recuperable, al tratarse no de una capacidad conductual, sino de un aspecto de organización social; el uso y fabricación de herramientas para procesar frutos o insectos, por su parte, podría inferirse, por ejemplo, por la presencia de restos vegetales en los yacimientos prehistóricos (ya que las herramientas jamás aparecerán debido a su naturaleza orgánica y perecedera). La falta de contraste informativo de la analogía formal (a pesar de que no deja de ser una analogía) la hace menos válida heurísticamente, por lo que Pickering y Domínguez-Rodrigo (2010) no dudan en denominarla como analogía trivial.

Llegamos ahora a nuestra propuesta de que el estudio de la conducta instrumental del chimpancé y otros primates no humanos es un gran refuerzo científico para investigar ciertos aspectos de la prehistoria, como la conducta instrumental de los australopitecinos y los primeros Homo. Esta conducta no se limitaría sólo a la talla lítica, sino que comprendería muchos comportamientos en contextos que van desde el agonismo a la consecución de recursos alimenticios. Además, debido a razonamientos de tipo filogenético, el hecho de que tanto 
el chimpancé como otros primates no humanos utilicen y fabriquen herramientas sería un argumento poderoso para corroborar la existencia de conducta instrumental en los primeros homínidos, ya que aquellas son especies menos complejas evolutivamente. Este tipo de razonamientos filogenéticos se han utilizado, por ejemplo, para inferir la existencia de otro tipo de comportamientos en el último antecesor común de los grandes simios a través de experimentos con orangutanes y bonobos (Mulcahy y Call 2006); básicamente, consiste en que si un par de especies poseen un comportamiento determinado, lo más probable es que ese comportamiento estuviese presente también en su antecesor o en otras especies entroncadas con ellas filogenéticamente.

Hay que señalar que respecto a las habilidades instrumentales del género Australopithecus, se poseen pocas evidencias (e. g. Semaw 2000) y se suelen poner en duda, por lo que nuestra propuesta adquiriría un gran valor heurístico en la reconstrucción de la prehistoria, algo que ya habían señalado otros autores desde distintos ámbitos científicos (Cleveland et al. 2004; Goodall 1986; McGrew 1992; Pickering y Domínguez-Rodrigo 2010; Wrangham 1987). Por razones como estas pensamos que los modelos primatológicos son un buen marco referencial para reconstruir una parte de la prehistoria.

Resumiendo, la conducta instrumental es un comportamiento característico de los primates (incluyendo a los homínidos) y de otros animales no humanos. Es, por tanto, una conducta con raíces biológicas y no culturales: no es una característica exclusivamente humana (aunque nuestra especie haya sido la que mejor ha sabido rentabilizarla evolutivamente).

Hemos visto también como los estudios con primates no humanos, en especial los realizados con grandes simios (y dentro de éstos los llevados a cabo con chimpancés), permiten la inferencia de analogías estructurales respecto al comportamiento de los primeros homínidos, especialmente aquellos que versan sobre la conducta instrumental. De este modo, las investigaciones etoarqueológicas representan una herramienta metodológica idónea para reconstruir ciertas fases de la prehistoria $(i . e$. origen de la humanidad y Paleolítico Inferior).

Asimismo, la abundante literatura primatológica existente respecto a la conducta instrumental en primates no humanos, nos hace ver lo limitado, muchas veces, de nuestra imaginación y creatividad a la hora de reconstruir el pasado cuando sólo utilizamos un solo camino (los yacimientos) para obtener datos e información, un camino que, si bien constituye la fuente más importante y fiable, no es en absoluto la única. Así, en todas las ilustraciones o imágenes de divulgación que tratan de reflejar el comportamiento de los primeros homínidos y transmitírselo a las personas no especializadas, casi siempre suele representárseles llevando a cabo actividades instrumentales como la talla lítica o el descarnado de presas, pero nunca envueltos en otras actividades como el forrajeo sobre insectos o frutos y la construcción de sus herramientas, así como en el uso de instrumentos para limpiarse o acicalarse, lo que es más que probable que llevaran a cabo.

Por último, debemos reclamar la atención de la arqueología prehistórica peninsular sobre este nuevo enfoque interdisciplinar para la arqueología de los orígenes humanos, ya que entonces podrá situarse en la vanguardia metodológica de la disciplina, al igual que ha hecho en la investigación concerniente a otras etapas prehistóricas (e. g. Neolítico, Edad del hierro, etc.) o con otros enfoques teóricos y metodológicos (arqueología posprocesual, etnoarqueología, etc.). Es por ello que esperamos que en años venideros crezca el interés de la arqueología prehistórica española por la primatología, y que se estrechen productivamente los precarios lazos que existen en la actualidad; aunque esto, quizá, constituya más un anhelo manifiesto que un vaticinio.

\section{Agradecimientos}

Este artículo está basado en el grueso de mi trabajo de tercer ciclo, leído en la Universidad Complutense de Madrid en septiembre de 2010. Su correcto desarrollo no podría haberse llevado a cabo sin los consejos y el apoyo de mis tutores, los doctores Manuel Domínguez-Rodrigo y Fernando Colmenares, así como de los perspicaces comentarios y juicios de los miembros del tribunal, la Dra. Almudena Hernando y el Dr. Víctor. M. Fernández. Quisiera agradecer también al Centro de Rescate de Primates Rainfer la oportunidad que me han concedido para trabajar y colaborar con ellos, pudiendo mejorar notablemente mi formación teórica y práctica en primatología.

\section{Notas}

1. Los primates no humanos son todos aquellos primates que no se encuentran dentro del género Homo y otros géneros cuyo cladograma está directa y recientemente relacionado con el ser humano, como Australopithecus o Ardipithecus. No obstante, pese a este consenso tácito, debemos señalar que, estrictamente hablando, ni australopitecos ni ardipitecos serían primates humanos, ya que no pertenecen al género homo. 
2. En los últimos años, algunos autores han optado por una nueva taxonomía que haría de los póngidos y los homínidos un solo grupo taxonómico, definiéndolos a todos como homínidos (Hominidae) y acuñando un nuevo término y taxón, Hominini (homininos), para definir a los primates humanos. Tal es el caso de Stringer y Andrews (2005: 16). Dado que se trata de una taxonomía no aceptada plenamente por la comunidad científica y que, además, puede dar pie a cierta confusión, hemos decidido utilizar la taxonomía primate tradicional señalada anteriormente (ver apartado 3).

\section{REFERENCIAS BIBLIOGRÁFICAS}

Amant, R. \& Horton, T. E. (2008): Revisiting the definition of animal tool use. Animal Behaviour, 75 (4): 1199 1208.

Barber, J. T.; Ellgaard, E. G.; Thien, L. B.; Stack, A. E. (1989): The use of tools for food transportation by the imported fire ant. Solenopsis invicta. Animal Behaviour, 38 (3): 550-552.

Beck, B. B. (1980): Animal tool behavior. The use and manufacture of tools by animals. Garland STPM Press, Nueva York.

Beck, B. B. (1972): Tool use in captive hamadryas baboons. Primates, 13 (3): 276-296.

BECK, B. B. (1973): Cooperative tool use by captive hamadryas baboons. Science, 182 (4112): 594-597.

BeCK, B. B. (1982): Chimpocentrism: bias in cognitive ethology. Journal of Human Evolution, 11(1): 3-17.

Bernardi, G. (2011): The use of tools by wrasses (Labridae). Coral Reefs, 30 (3): 865.

Berthelet, A.; Chavaillon, J. (eds) (1993): The use of tools by human and non-human primates. Oxford University Press, Nueva York.

Binford, L. R. (1962): Archaeology as anthropology. American Antiquity, 28 (2): 217-225.

Boesch, C. (2003): Is culture a golden barrier between human and chimpanzee? Evolutionary Anthropology, 12 (2): 82-91.

Boesch, C.; Boesch, H. (1981): Sex differences in the use of natural hammers by wild chimpanzees: a preliminary report. Journal of Human Evolution, 10 (7): 585-593.

Boesch, C.; Boesch, H. (1983): Optimisation of nut-cracking with natural hammers by wild chimpanzees. Behaviour, 3-4: 265-286.

Boesch, C.; Boesch, H. (1984): Mental map in wild chimpanzees: an analysis of hammer transports for nut cracking. Primates, 25 (2): 160-170.

Boesch, C.; Boesch, H. (1990): Tool use and tool making in wild chimpanzees. Folia Primatologica, 54 (1-2): 86-99.

BoInski, S. (1988): Use of a club by a wild white-faced capuchin (Cebus capucinus) to attack a venomous snake (Bothrops asper). American Journal of Primatology, 14 (2): 177-179.

Boyd, R.; Silk, J. B. (2009): How humans evolved. University of California Press, Los Angeles.

Breuer, T.; Ndoundou-Hockemba, M.; Fishlock, V. (2005): First observation of tool use in wild gorillas. PLos Biology, 3 (11): 2041-2043.

Byrne, R. A.; Burghardt, G. M.; Kuba, M. J. (2010): A new method for study problem solving and tool use in stingrays (Potamotrigon castexi). Animal Cognition, 13 (3): 507-513.

CAll, J. (1996): El uso y fabricación de instrumentos en los primates. Un enfoque multidisciplinar. Etología, psicología comparada y comportamiento animal (F. Colmenares, ed.), Síntesis, Madrid: 483-514.

Carpenter, A. (1887): Monkeys opening oysters. Nature, 36: 53.

Chappell, J.; KaCelniK, A. (2002): Tool selectivity in a non primate, the New Caledonian crow (Corvus moneduloides). Animal Cognition, 5 (2): 71-78.

Cleveland, A.; Rocca, A. M.; Wendt, E. L.; Westergaard, G. C. (2004): Transport of tools to food sites in tufted capuchin monkeys (Cebus apella). Animal Cognition, 7 (3): 193-198.

Colmenares, F. (1996): Etología, Biología y Psicología: relaciones interdisciplinares. En F. Colmenares, ed., 1996: 51-112.

Cunningham, C. L.; Anderson, J. R.; Mootnick, A. R. (2006): Object manipulation to obtain a food reward in hoolock gibbons, Bunopithecus hoolock. Animal Behaviour, 71 (3): 621-629.

Domínguez-Rodrigo, M. (1994): Dinámica trófica, estrategias de consumo y alteraciones óseas en la sabana africana: resumen de un proyecto de investigación etoarqueológico (1991-1993). Trabajos de Prehistoria, 51 (1): 15-37. 
Dunbar, R. I. M. (1998): The social brain hypothesis. Evolutionary Anthropology, 6 (5): 178-190.

Dunbar, R. I. M.; Shultz, S. (2007): Evolution in the social brain. Science, 317 (5843): 1344-1347.

Finn, J., Tregenza, T.; Norman, M. D. (2009): Defensive tool use in a coconut-carrying octopus. Current Biology, 19 (2): 1069-1070.

Fragaszy, D. M.; Visalberghi, E.; Fedigan, L. M. (2004): The complete capuchin. The biology of the genus Cebus. Cambridge University Press, Cambridge.

Fragaszy, D.; Izar, P.; Visalberghi, E.; Ottoni, E. B.; De Oliveira, M. G. (2004): Wild capuchin monkeys (Cebus libinidosus) use anvils and stone pounding tools. American Journal of Primatology, 64 (4): 359-366.

Galdikas, B. M. F. (1982): Orang-utan tool-use at Tanjung Putting Reserve, Central Indonesian Borneo (Kalimantan Tengah). Journal of Human Evolution, 11 (1): 19-33.

GeIssmann, T. (2009): Door slamming: Tool-use by a captive white-handed gibbon (Hylobates har). Gibbon Journal, 5: 53-60.

Gómez, J. C. (1989): La comunicación y la manipulación de objetos en crías de gorila. Estudios de Psicología, 38: $111-128$

Goodall, J. (1964): Tool-using and aimed throwing in a community of free-living chimpanzees. Nature, 201(4926): 1264-1266.

Goodall, J. (1986): En la senda del hombre. Salvat, Barcelona.

Griffin, D. R. (1992): Animal minds. The University of Chicago Press, Chicago.

Hall, K. R. L. (1963): Tool-using performances as indicators of behavioral adaptability. Current Anthropology, 4 (5): 479-494.

Hart, B. L.; Hart, L. A.; McCoy, M.; Sarath, C. R. (2001): Cognitive behavior in Asian elephants: use and modification of branches for fly switching. Animal Behaviour, 62 (5): 839-847.

Haslam, M.; Hernández-Aguilar, A.; Ling, V., Carvalho, S.; de la Torre, I.; DeStefano, A.; Du, A.; Hardy, B.; Harris, J.; Marchant, L.; Matsuzawa, T.; McGrew, W.; Mercader, J.; Mora, R.; Petraglia, M.; Roche, H.; Visalberghi, E.; Warren, R. (2009): Primate archaeology. Nature, 460 (7253): 339-344.

Hernando, A. (1995): La etnoarqueología hoy: una vía eficaz de aproximación al pasado. Trabajos de Prehistoria, 52 (2): $15-30$.

IzAWA, K.; Mizuno, A. (1977): Palm-fruit cracking behavior of wild black-capped capuchin (Cebus apella). Primates, 18 (4): 773-792.

Kano, T. (1982): The use of leafy twigs for rain cover by the pygmy chimpanzees of Wamba. Primates, 23 (3): $453-457$.

Kitahara-Frisch, J.; Norikoshi, K.; Hara, K. (1987): Use of a bone fragment as a step towards secondary tool use in captive chimpanzee. Primate Report, 18: 33-37 (citado en Tomasello y Call, 1997).

KÖHLER, W. (1989 [1921]): Experimentos sobre la inteligencia de los chimpancés. Editorial Debate, Madrid.

Kunn, T. S. (2000): La estructura de las revoluciones cientificas. Fondo de Cultura Económica, México D. F.

LAKATOS, I. (1974): Historia de la ciencia y sus reconstrucciones racionales. Tecnos, Madrid.

Lethmate, J. (1982): Tool-using skills of orang-utans. Journal of Human Evolution, 11 (1): 49-64.

McGrew, W. C. (1992): Chimpanzee material culture. Implications for human evolution. Cambridge University Press, Cambridge.

McGrew, W. C. (1993): The intelligent use of tools: twenty propositions. Tools, language and cognition in human evolution (K. R. Gibson y T. Ingold eds.), Cambridge University Press, Cambridge: 151-170.

McGrew, W. C.; Baldwin, P. J.; Marchant, L. F.; Pruetz, J. D.; Scott, S. D.; Tutin, C. E. G. (2003): Ethoarchaeology and elementary technology of unhabituated wild chimpanzees at Assirik, Senegal, West Africa. Paleoanthropology, 1: 1-20.

Mulcahy, N. J.; Call, J. (2006): Apes save tools for future use. Science, 312 (5776): 1038-1040.

NishidA, T. (1973): The ant-gathering behavior by the use of tools among wild chimpanzees of the Mahali Mountains. Journal of Human Evolution, 2 (5): 357-370.

Nishida, T. (1980): The leaf-clipping display: a newly-discovered expressive gesture in wild chimpanzees. Journal of Human Evolution, 9 (2): 117-128.

OAKLeY, K. P. (1950): Man the tool-maker. The Trustees of the British Museum, Londres.

PARKer, S. T.; Gibson, K. R. (1977): Object manipulation, tool use and sensorimotor intelligence as feeding adaptations in Cebus monkeys and Great Apes. Journal of Human Evolution, 6 (7): 623-641. 
Pickering, T.; Domínguez-Rodrigo, M. (2010): Chimpanzee referents and the emergence of human hunting. The Open Anthropology Journal, 3: 107-113.

Popper, K. (2007): Conocimiento objetivo. Un enfoque evolucionista. Tecnos, Madrid.

Pouydebat, E.; Berge, C.; Gorce, P.; Coppens, Y. (2005): Use and manufacture of tools to extract food by captive Gorilla gorilla gorilla: experimental approach. Folia Primatologica, 76 (3): 180-183.

Prigogine, I.; Stengers, I. (2004): La nueva alianza. Metamorfosis de la ciencia. Alianza Editorial, Madrid.

Pruetz, J. D.; Bertolani, P. (2007): Savanna chimpanzees, Pan troglodytes verus, hunt with tools. Current Biology, 17 (5): 412-417.

Rowe, N. (1996): The pictorial guide to the living primates. Pogonias Press, Charleston.

Sabater Pi, J. (1972): Bastones fabricados y usados por los chimpancés de las montañas de Okorobikó (Río Muni), Rep. Guinea Ecuatorial. Ethnica. Revista de Antropología, 4: 189-199.

Sabater Pi, J. (1974a): An elementary industry of the chimpanzees in the Okorobikó mountains, Rio Muni (Republic of Equatorial Guinea) West Africa. Primates, 15 (4): 351-364.

Sabater Pi, J. (1974b): Protoculturas materiales e industrias elementales de los chimpancés en la naturaleza. Ethnica. Revista de Antropología, 7: 231-226.

SABAter Pi, J. (1992): El chimpancé y los orígenes de la cultura. Anthropos, Barcelona.

SAntos, L. R.; Mahajan, N.; Barnes, J. L. (2005): How prosimian primates represent tools: experiments with two lemur species (Eulemur fulvus and Lemur catta). Journal of Comparative Psychology, 119 (4): $394-403$.

Savage-Rumbaugh, S.; Lewin, R. (1994): Kanzi. The ape at the brink of the human mind. Doubleday, Londres.

Schick, K. D.; Toth, N.; Garufi, G.; Savage-Rumbaugh, E. S.; Rumbaugh, D.; Sevcik, R. (1999): Continuing investigations into the stone tool-making and tool using capabilities of a bonobo (Pan paniscus). Journal of Archaeological Science, 26 (7): 821-832.

SEmaw, S. (2000): The world's oldest stone artifacts from Gona, Ethiopia: their implications for understanding stone technology and patterns of human evolution between 2.6-1.5 million years ago. Journal of Archaeological Science, 27 (12): 1197-1214.

Serrallonga, J. (1994): Homo faber, el fin de un mito. Etología y Prehistoria, una aproximación al Presente para reconstruir el Pasado del útil. Pyrenae, 25: 31-49.

Serrallonga, J. (2005): No estamos solos: australopitecos y chimpancés habilidosos. Existo, luego pienso. Los primates y la evolución de la inteligencia humana (F. Guillén-Salazar, ed.), Ateles Editores, Madrid: 171-251.

SinHA, A. (1997): Complex tool manufacture by a wild bonnet macaque. Macaca radiate. Folia Primatologica, 68 (1): 23-25.

Shumaker, R. W.; Walkup, K. R.; Beck, B. B. (2011): Animal tool behavior. The use and manufacture of tools by animals (Revised and updated edition). The Johns Hopkins University Press, Baltimore.

Stornski, T. S.; Beck, B. B. (2001): Spontaneous tool use in captive, free-ranging Golden Lion Tamarins (Leontopithecus rosalia rosalia). Primates, 42 (4): 319-326.

Stringer, C.; Andrews, P. (2005): The complete world of human evolution. Thames and Hudson, Londres.

Taylor, A. H.; Hunt, G. R.; Holzhaider, J. C.; Gray, R. D. (2007): Spontaneous metatool use by New Caledonian Crow. Current Biology, 17 (17): 1504-1507.

Tebirch, S.; Bshary, R. (2004): Cognitive abilities related to tool use in the woodpecker finch, Cactospiza pallida. Animal Behaviour, 67 (4): 689-697.

TELEKI, G. (1974): Chimpanzee subsistence technology: materials and skills. Journal of Human Evolution, 3 (6): $575-594$.

Tokida, E.; TAnaka, I.; Takefushi, H.; Hagiwara, T. (1994): Tool-using in Japanese macaques: use of stones to obtain fruit from a pipe. Animal Behaviour, 47 (5): 1023-1030.

Tomasello, M.; Call, J. (1997): Primate Cognition. Oxford University Press, Nueva York.

Toth, N.; Schick, K. D.; Savage-Rumbaugh, E. S.; Sevcik, R. A.; Rumbaugh, D. M. (1993): Pan the tool-maker: investigations into the stone tool-making and tool-using capabilities of a bonobo (Pan paniscus). Journal of Archaeological Science, 20 (1): 81-91.

Van Schaik, C. P.; Fox, E. A.; Sitompul, A. F. (1996): Manufacture and use of tools in wild Sumatran orangutans. Naturwissenschaften, 83 (4): 186-188.

VeÁ, J.; Clemente, I. (1988): Conducta instrumental del chimpancé (Pan troglodytes) en su hábitat natural. Anuario de Psicología, 39 (2): 28-66. 
Visalberghi, E.; Fragaszy, D.; Ottoni, E. B.; De Oliveira, M. G.; Andrade, F. R. D. (2007): Characteristics of hammer stones and anvils used by wild bearded capuchin monkeys (Cebus libidinosus) to crack open palm nuts. American Journal of Physical Anthropology, 132 (3): 426-444.

Visalberghi, E.; Addessi, E.; Truppa, V.; Spagnoletti, N.; Ottoni, E. B.; Izar, P.; Fragaszy, D. (2009): Selection of effective stone tools by wild bearded capuchin monkeys. Current Biology, 19 (3): 213-217.

Westergand, G. C.; Fragaszy, D. M. (1987): The manufacture and use of tools by capuchin monkeys (Cebus apella). Journal of Comparative Psychology, 101 (2): 159-168.

Westergaard, G. C.; Suomi, S. J. (1993): Use of a tool-set by a capuchin monkey. Primates, 34 (4): $459-462$.

Westergaard, G. C.; Suomi, S. J. (1994a): The use and modification of bone tools by capuchin monkeys. Current Anthropology, 35 (1): 75-77.

Westergatrd, G. C.; Suomi, S. J. (1994b): Stone-tool bone-surface modification by monkeys. Current Anthropo$\log y, 35$ (4): 468-470.

Westergatrd, G. C.; Suomi, S. J. (1994c): A simple stone-tool technology in monkeys. Journal of Human Evolution, 27 (4): 399-404.

Whiten, A.; Goodall, J.; McGrew, W. C.; Nishida, T.; Reynolds, V.; Sugiyama, Y.; Tutin, C. E. G.; Wrangham, R. W.; Boesch, C. (2001): Charting cultural variation in chimpanzees. Behaviour, 138 (11-12): 1481-1516.

Wrangham, R. W. (1987): The significance of African apes for reconstructing human social evolution en. The evolution of human behavior: primate models (W. Kinzey, ed.), State University of New York Press, Albany: 51-71. 